\title{
Isothermal Thermogravimetric Analysis of Recycled Carbon Fiber Composites
}

\author{
Seyed Hossein Mamanpush ${ }^{1 *}$, Reyhaneh Tavousi Tabatabaei ${ }^{2}$ and Bahareh Tavousi Tabatabaei ${ }^{2}$ \\ ${ }^{1}$ Composite Materials and Engineering Center, Washington State University, Pullman, WA, 99163, USA
}

${ }^{2}$ Department of Engineering, Islamic Azad University, Khomeyni Shahr Branch, Isfahan, Iran

*Corresponding author: Seyed Hossein Mamanpush, Composite Materials and

Received Date: November 16, 2018

Engineering Center, Pullman, WA, 99163, USA.

\begin{abstract}
Isothermal Thermogravimetric Analysis (TGA) is a technique in which the mass of a substance is monitored as a function of time as the sample specimen is subjected to a controlled temperature program in a controlled atmosphere. In this research, isothermal TGA was carried out to determine the thermal stability of the recycled epoxy-based and vinyl ester-based carbon fiber composite (CFC). The specimens were heated at constant temperature under nitrogen and air. We evaluate the influence of different temperature on the degradation of recycled CFCs. Results indicate that different temperature has significant influence on the degradation of the recycled CFC under nitrogen.
\end{abstract}

\section{Introduction}

A TGA can be used for materials characterization through analysis of characteristic decomposition patterns [1]. It is an especially useful technique for the study of polymeric materials, including thermoplastics, thermosets, elastomers, composites, plastic films, fibers [2-3] in this research we analyzed recycled epoxy-based CFC and vinyl ester-based CFCs isothermal stability. Each specimen was heated for $25 \mathrm{~min}$ [4-5]. For each specimen, it takes around $7 \mathrm{~min}$ that we reach the targeted temperature [6-8].

Isothermal TGA results of epoxy-based CFC shows that by increasing the isothermal temperature, degradation increased. After $25 \mathrm{~min}$. At $340{ }^{\circ} \mathrm{C}$ the epoxy-based $\mathrm{CFC}$ material has the remaining of $88 \%$ and at $380{ }^{\circ} \mathrm{C}$ it is around $77 \%$.

After 25 min., vinyl ester-based CFC material has the remaining of $89 \%$ at $340{ }^{\circ} \mathrm{C}$ and $73 \%$ at $380{ }^{\circ} \mathrm{C}$. (figure $1 \& 2$ ). Results indicates that epoxy-based CFC and vinyl ester-based CFC have similar trend of degradation under nitrogen [9-10].

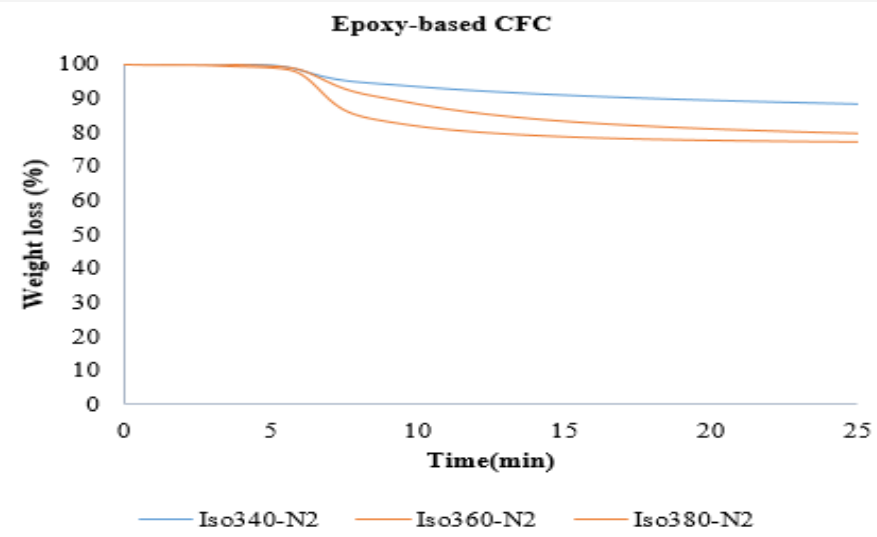

Figure 1: Isothermal TGA curve of epoxy-based CFC recorded in nitrogen (considering the influence of temperature). 


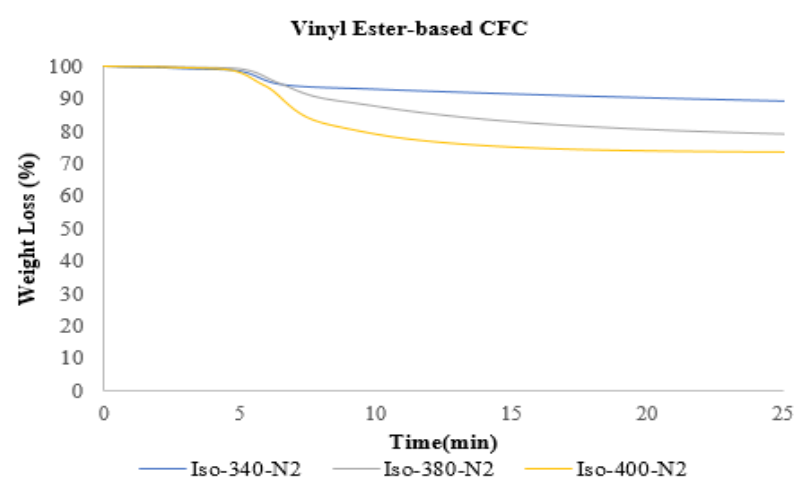

Figure 2: Isothermal TGA curve of vinyl ester-based CFC recorded in nitrogen (considering the influence of temperature).

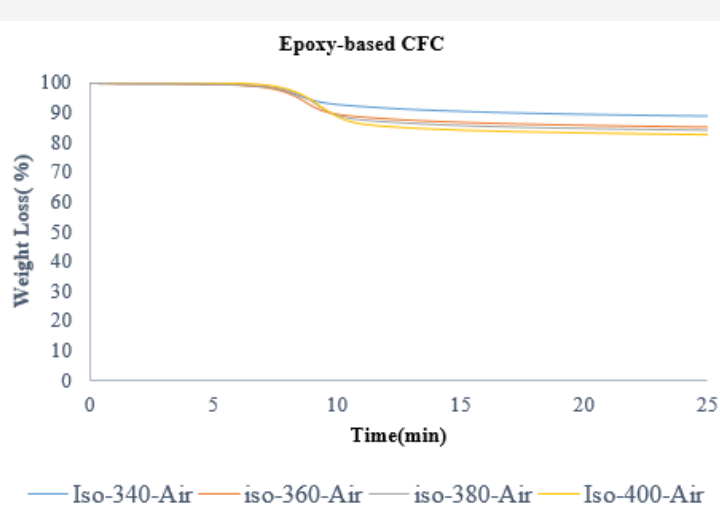

Figure 3: Isothermal TGA curve of epoxy-based CFC recorded in air (considering the influence of temperature).

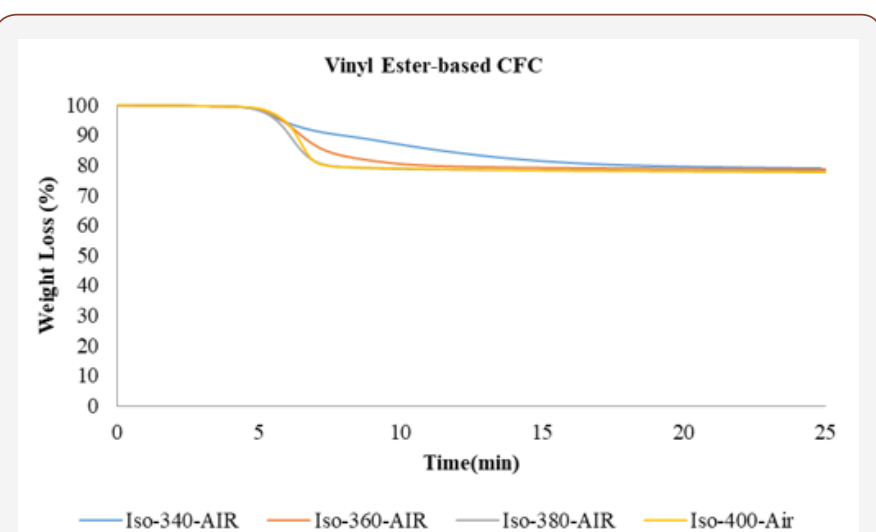

Figure 4: Isothermal TGA curve of vinyl ester-based CFC recorded in air (considering the influence of temperature).

Isothermal TGA results of epoxy-based CFC shows similar trend (Figure $3 \& 4$ ). After 25 Min. the remaining of epoxy-based $\mathrm{CFC}$ is $88 \%, 85 \%, 83 \%$ and $82 \%$ at $340{ }^{\circ} \mathrm{C}, 360^{\circ} \mathrm{C}, 380{ }^{\circ} \mathrm{C}$ and 400 ${ }^{\circ} \mathrm{C}$ respectively. Isothermal TGA results of vinyl ester-based $\mathrm{CFC}$ indicates that by increasing the temperature degradation happened faster. After 25min, the vinyl ester-based CFC has the remaining of $77 \%$ for almost every temperature.

The isothermal TGA results of recycled CFCs is a key factor for manufacturing the second-generation composites from recycled materials. Isothermal TGA results of epoxy-based CFC and vinyl ester-based CFC indicate that there is a safe zone for processing these materials. For all the samples isothermal results is almost consistent after $7 \mathrm{~min}$. and no degradation happened after that.

\section{Acknowledgement}

None.

\section{Conflict of Interest}

No Conflict of Interest.

\section{References}

1. Hui Li, Karl Englund (2016) Recycling of carbon fiber-reinforced thermoplastic composite wastes from the aerospace industry. Journal of Composite Materials 51(9): 1265-1273.

2. Mamanpush H, Golestanian H (2014) Investigating the effects of carbon nanotube orientation on the macroscopic stiffness of nanocomposites. Int J Curr Life Sci 4(4): 1168-1174.

3. Mamanpush H, Golestanian H (2014) Evaluation of effective material properties of randomly distributed carbon nanotube composites considering interface effect. Indian J Sci Res 2(1): 132-142.

4. Thostenson ET, Karandikar PG, Chou TW (2005) Fabrication and characterization of reaction bonded silicon carbide/carbon nanotube composites. J Phys D Appl Phys 38(21): 3962-3965.

5. Song YS, Youn JR (2006) Modeling of effective elastic properties for polymer-based carbon nanotube composites. Polymer 47(5): 17411748.

6. Mamanpush H, Golestanian H (2014) Effects of carbon nanotube dispersion on the mechanical properties of nanocomposites considering interface effect. International Journal of Current Research 4(8): 43664373.

7. Seyed Hossein Mamanpush, Hui Li, Karl Englund, Azadeh Tavousi Tabatabaei (2018) Recycled wind turbine blades as a feedstock for second generation composites. Waste Management 76: 708-714.

8. Seyed Hossein Mamanpush, Azadeh Tavousi Tabatabaei, Hui Li, Karl Englund (2018) Data on the mechanical properties of recycled wind turbine blade composites. Data in Brief 19: 230-235.

9. Seyed Hossein Mamanpush, Hui Li, Karl Englund, Azadeh Tavousi Tabatabaei (2018) Dataset demonstrating physical properties of recycled wind turbine blade composites. Data in Brief 20: 658-661.

10. Seyed Hossein Mamanpush, Azadeh Tavousi Tabatabaei (2018) Innovative Method in Recycling Wind Turbine Blades: Mini Review. Evolutions Mech Eng 1(1): 1-2.

11. Seyed HM, Zohre MG, Hossein G (2018) Numerical Modeling of Nano Bundle and Nano Rope-Reinforced Polymer Mechanical Properties. Evolutions Mech Eng 1(4): 1-9.

12. Azadeh Tavousi Tabatabaei, Seyed Hossein Mamanpush, Bahareh Tavousi Tabatabaei (2018) Effects of Carbon Nanotube Dispersion on the Material Properties of Polymer Matrix Composites. Evolutions Mech Eng 1(3). 